\title{
Tswana Language
}

National Cancer Institute

\section{Source}

National Cancer Institute. Tswana Language. NCI Thesaurus. Code C154176.

A Niger-Congo Bantu language spoken in Southern Africa and as an official language of Botswana. 